\title{
Slotting Allowances as a Facilitating Practice by Food Processors in Wholesale Grocery Markets: Profitability AND WeLfare EFFECTS
}

\author{
STEPHEN F. HAMILTON
}

\begin{abstract}
Slotting allowances, which are lump-sum transfers paid by food manufacturers to grocery retailers in return for various retail concessions, are becoming increasingly common in wholesale grocery markets. This article extends the literature on slotting allowances by considering two features that previously have been ignored: the role of food processors in determining these pricing arrangements, and the effect of slotting allowances on the size and distribution of economic surplus. Slotting allowances motivated by food processors increase procurement quantities and farm prices, and this raises farm surplus, increases total producer surplus, and improves consumer welfare in the food system.
\end{abstract}

Key words: oligopsony; rent-shifting; slotting allowances; vertical market structure.

Slotting allowances are lump-sum fees paid by food manufacturers to grocery retailers in exchange for access to the consumer market. Slotting allowances per se emerged in 1984 and have since become an increasingly common practice in wholesale supermarket transactions. While the term "slotting allowance" technically refers to a charge collected by a grocery retailer in exchange for shelf space (computer inventory systems divide shelf space at supermarkets into "slots"), the term is often used generically to describe various types of wholesale payments, such as introductory fees for new products, periodic stocking fees for existing products, floor charges for the manufacturer to make sales presentations, and display fees for special merchandising and promotion. The salient characteristic that unifies this payment structure is that the slotting allowance is a lump-sum charge that does not vary with subsequent retailer sales.

There is considerable disagreement in the literature on the purpose slotting allowances serve. At the center of the debate is the important policy question of whether slotting al-

Stephen F. Hamilton is associate professor in the Department of Economics, University of Central Florida.

The author thanks Ramarao Desiraju, Robert Innes, Kyle Stiegert, Gary Thompson, editor Ian Sheldon, seminar participants at the University of Wisconsin and the University of Arizona, and two journal reviewers for their helpful comments. Responsibility for any remaining errors is, of course, the author's alone. lowances have procompetitive or anticompetitive effects in the food system. ${ }^{1}$

The procompetitive view of slotting allowances is that lump-sum payments act as an instrument to ration new product introductions. Under circumstances in which agents have asymmetric information on the quality of a new product, a slotting allowance can enhance efficiency by serving as a signaling or screening device (Lariviere and Padmanabhan, Sullivan, Richards and Patterson). The basic idea is that when manufacturers have superior information regarding the quality of new products, slotting allowances mitigate the moral-hazard problem by allocating shelf space only to new products that exceed a threshold level of quality, which reduces the rate of product failure. This argument provides a compelling explanation for introductory fees; however, it also raises an important unanswered question. If slotting allowances indeed exist to align incentives under asymmetric information, then why do food manufacturers also pay slotting allowances on well-established products for which brand acceptance is reasonably well understood? Slotting allowances are also paid to retailers on a periodic basis to maintain shelf space on existing products.

\footnotetext{
${ }^{1}$ This question is also at the heart of the broader literature on vertical restraints.
} 
The simularity of the payment structure that supports slotting allowances for new product introductions and for periodic activities such as stocking, displaying, merchandising, and promotion suggests the need to develop a unifying theory that encompasses all forms of two-part tariff arrangements in the wholesale grocery market.

The anticompetitive view of slotting allowances is that lump-sum payments act as an instrument for retailers to exercise market power. Imperfectly competitive retailers have an incentive to use slotting allowances either as a mechanism to price discriminate among manufacturers (Cannon and Bloom, Desiraju) or as a facilitating practice to reduce downstream price competition in the consumer market (Shaffer). The essence of Shaffer's argument, which is closely related to the argument made here, is that a retailer can use revenue collected from a slotting allowance to support the payment of a higher wholesale grocery price. The payment of a higher wholesale price has no direct effect on the retailer's profitthe cost of this is exactly offset by the slotting allowance-but is profitable nonetheless for its indirect effect on the behavior of rival grocery retailers. A high wholesale price signals rival retailers the intent to set a correspondingly high price in the retail market, and this softens downstream price competition.

A merit of the anticompetitive view is that retail market power provides a unifying motivation to explain all forms of two-part tariffs in the wholesale grocery market. However, there is a sense in which the retail market power story overfits the practice. If slotting allowances emerge as a mechanism for retailers to exercise market power, then this raises the question of why the fees are systematically levied only in processed food categories of the supermarket? Slotting allowances are frequently exchanged in highly concentrated, processed product categories such as frozen and refrigerated foods, dry grocery, beverages, snacks, candy, and microwaveable shelf-stable foods. In the much-studied product class of fresh produce, by contrast, it is exclusively the shippers of bagged salad and other freshcut, branded products-food processors, not commodity producers-who pay slotting allowances to retailers (Calvin et al.).

This article develops a theory of slotting allowances around food processor market power. The theory encompasses all forms of two-part tariff arrangements observed in wholesale grocery markets, yet provides some insight to explain why the practice has emerged in some product categories but not in others. Given the importance of the processing sector as a source of value-added in the food system, it is somewhat surprising to note that the role of food processors in determining arrangements for slotting allowances is a subject that has been entirely ignored.

The observations developed here are based on a vertical market framework in which food production is organized between an upstream farm product market and a series of downstream markets (wholesale and retail) for differentiated processed goods. In the upstream market, competitive farm producers sell a homogeneous farm product to imperfectly competitive food processors. This conceptual treatment of the farm product market joins an emerging literature in this journal on imperfect competition in the food system, which posits an oligopsonistic relationship between farm producers and food processors (see, e.g., Sexton, Chen and Lent, Wann and Sexton, Hamilton and Sunding). This focus on food processor behavior provides a formal link between the farm product market and the wholesale grocery market that allows welfare implications to be derived in terms of the size and distribution of economic surplus at all stages of the food system.

The model produces several notable welfare implications. Unlike the case of two-part tariffs that arise through retailer market power, slotting allowances motivated by processor market power raise farm surplus; increase the combined producer surplus of farmers, processors, and retailers; and improve consumer welfare (under both consumer surplus and utilitybased measures).

\section{The Model}

The starting point for the analysis is a vertical food system comprising a single upstream market and a single downstream market. In the upstream market, competitive firms sell a homogeneous farm product to an oligopsonistic food processing industry, and, in the downstream market, the food processors sell a finished processed good to grocery retailers at the wholesale level. Further downstream, of course, is the retail market between grocery retailers and consumers. However, because the central forces of the model operate on incentives that develop through the multimarket contact of food processors at the upstream and 


$\begin{array}{lll}\text { Contract Stage: } & \begin{array}{l}\text { Acceptance Stage: } \\ \text { Food processors } \\ \text { choose contract } \\ \text { terms }\left(\hat{p}_{i}, \hat{s}_{i}, i=1,2\right)\end{array} \longrightarrow \begin{array}{l}\text { Procurement Stage: } \\ \text { accept or reject the } \\ \text { contract }\end{array} \begin{array}{l}\text { Food processors } \\ \text { choose procurement } \\ \text { levels of the farm } \\ \text { product }\left(x_{i}, i=1,2\right)\end{array}\end{array}$

\section{Figure 1. The timing of the game}

wholesale levels of the food system, the retail market, which plays no direct role in the analysis, is initially suppressed by assuming a competitive retail industry. The model is then extended to encompass consumer markets (and potentially noncompetitive retailers) in subsequent sections.

The model considers slotting allowances that arise in a fixed price contract form. A fixed price contract, which specifies a wholesale price and a lump-sum transfer, is a commonly employed contract form in wholesale grocery markets (Calvin et al.).

Consider an upstream industry that produces a homogeneous farm product. ${ }^{2}$ The farm product is sold in an oligopsony market comprising $n$ food processing firms. The level of farm product use by processor $i$ is denoted $x_{i}$ and total farm product use in the industry is $X=\sum_{i} x_{i}$. The price in the farm product market is given by the (inverse) farm supply function, which is denoted by $p^{f}(X)$, with $p_{x}^{f}(X) \equiv d p^{f}(X) / d X>0$. The farm product is used by processor $i$ to produce a (differentiated) finished processed good, $y_{i}$, according to the production function $y_{i}=f^{i}\left(x_{i}\right)$, and this satisfies $f_{x}^{i}\left(x_{i}\right) \equiv d f^{i}\left(x_{i}\right) / d x_{i}>0$ and $f_{x x}^{i}\left(x_{i}\right) \equiv d^{2} f^{i}\left(x_{i}\right) / d x_{i}^{2} \leq 0$. In the absence of a slotting allowance, food processor $i$ sells her finished processed good to competitive retail buyers at a noncontracted wholesale price of $p_{i}^{w}$.

Strategic interaction between food processors is modeled as a three-stage game, the timing of which is described in figure 1 . In the first stage, the contract stage, food processor $i$ writes an observable and non-renegotiable contract with one or more of her downstream retailers. Letting a hat on a variable denote a term specified in a slotting contract, the contract of processor $i$ specifies a wholesale price for the $\operatorname{good}\left(\hat{p}_{i}\right)$ and a lump-sum transfer

\footnotetext{
${ }^{2}$ When the upstream farm product market is heterogeneous, as would be the case when farm suppliers produce locationally differentiated commodities, the qualitative predictions for the optimal processor contract are identical to those described here. For the interest of model clarity, this consideration is suppressed here.
}

$\left(\hat{s}_{i}\right)$ to be paid to the retailer. The equilibrium value of this lump-sum transfer is allowed to emerge without restriction on sign. In the second stage, the retailer either accepts or rejects the processor's contract. If the contract is accepted, the food processor pays a slotting allowance of $\hat{s}_{i}$ to the retailer in return for the retailer's agreement to purchase the processed good at a contracted wholesale price of $\hat{p}_{i}$. If the contract is rejected, then no slotting allowance is paid and the food processor sells her good to the retailer at the noncontracted wholesale price, $p_{i}^{w}$. In the third and final stage, the food processors compete in a Cournot oligopsony to procure the farm product.

Throughout, it is assumed that

$$
p_{x}^{f}(X)+x_{i} p_{x x}^{f}(X)>0, \quad \text { for all } i
$$

which guarantees the existence and stability of the farm product equilibrium. ${ }^{3}$ Condition (1) ensures that the marginal profit of each processor declines with the procurement level of the rival processors (i.e., that reaction functions slope downward).

The model is solved using backward induction. Hence, the analysis begins with the procurement stage, followed by the acceptance and contract stages, respectively. To make the analysis more transparent, attention is confined to the duopsony case.

Suppose the downstream retailer has accepted the contract proposed by food processor $i$ in the procurement stage. In this case, the objective function of processor $i$ is

$$
\begin{aligned}
& \pi^{i}\left(x_{i}, X, \hat{p}_{i}, \hat{s}_{i}\right) \\
& \quad=\hat{p}_{i} f^{i}\left(x_{i}\right)-p^{f}(X) x_{i}-\hat{s}_{i} \quad i=1,2 .
\end{aligned}
$$

In addition, there is also a sunk cost component that explains the existence of imperfect competition in the processing sector; however, this plays no role in the analysis and is

\footnotetext{
${ }^{3}$ Expression (1) is sufficient for the Routh-Hurwitz condition to hold on the Jacobian of equations (3).
} 
consequently omitted. Maximizing (2) with respect to $x_{i}$ yields the necessary condition

$$
\begin{array}{r}
\pi_{i}^{i} \equiv \hat{p}_{i} f_{x}^{i}\left(x_{i}\right)-p^{f}(X)-x_{i} p_{x}^{f}(X)=0 \\
i=1,2
\end{array}
$$

The level of farm product use by each firm and total industry use of the farm product are obtained in the procurement stage by simultaneously solving equations (3). Denote these solution values by the vectors $x_{i}^{c} \equiv x_{i}^{c}\left(\hat{p}_{1}, \hat{p}_{2}\right), i=$ 1,2 and $X^{c} \equiv X^{c}\left(\hat{p}_{1}, \hat{p}_{2}\right)$. Throughout, the convention is to suppress the arguments of $x_{i}^{c}$ and $X^{c}$ except when denoting the evaluation of these vectors at particular values of the contract prices.

Totally differentiating (3) yields the comparative statics effects associated with the processor's choice of $\hat{p}_{i}$. Noting that $\pi_{i i}^{i}<0, \pi_{i j}^{i}<0$, and $\Delta=\pi_{i i}^{i} \pi_{j j}^{j}-\pi_{i j}^{i} \pi_{j i}^{j}>0$ by (1), the comparative statics effects are

$$
\frac{\partial x_{i}^{c}}{\partial \hat{p}_{i}}=\frac{-f_{x}^{i}\left(x_{i}^{c}\right) \pi_{j j}^{j}}{\Delta}>0
$$

and

$$
\frac{\partial x_{j}^{c}}{\partial \hat{p}_{i}}=\frac{f_{x}^{i}\left(x_{i}^{c}\right) \pi_{j i}^{j}}{\Delta}<0 .
$$

Next define the ratio of comparative statics effects in (4) and (5) as

$$
\begin{aligned}
& \frac{\partial x_{j}}{\partial x_{i}}\left(x_{j}^{c}, X^{c}\right) \\
& \equiv \frac{\partial x_{j}^{c} / \partial \hat{p}_{i}}{\partial x_{i}^{c} / \partial \hat{p}_{i}} \\
& =\frac{p_{x}^{f}\left(X^{c}\right)+x_{j}^{c} p_{x x}^{f}\left(X^{c}\right)}{\hat{p}_{j} f_{x x}^{j}\left(x_{j}^{c}\right)-2 p_{x}^{f}\left(X^{c}\right)-x_{j}^{c} p_{x x}^{f}\left(X^{c}\right)}
\end{aligned}
$$

which is negative by the stability condition (1) and the second-order condition of processor $j$.

A retailer is willing to accept the slotting contract proposed by a processor provided he receives a payment no less than his opportunity costs. With a competitive retail industry, these opportunity costs can be normalized to zero without loss of generality. Accordingly, the retailer accepts the contract proposed by processor $i$ whenever

$$
\left(p_{i}^{w}-\hat{p}_{i}\right) y_{i}+\hat{s}_{i} \geq 0, \quad i=1,2 .
$$

In (7), processor $i$ compensates the retailer for any departure of the contracted price from the noncontracted wholesale price through the payment of a slotting allowance.

In the contract stage, processor $i$ chooses the terms of the contract so as to maximize profits in (2) subject to the participation constraint (7) and the procurement stage solutions above. Substituting the procurement stage solutions into (2) and (7), the contracting problem is

$$
\begin{aligned}
& \operatorname{Max}_{\hat{p}_{i}, \hat{s}_{i}} \pi^{i}\left(\hat{p}_{1}, \hat{p}_{2}, \hat{s}_{i}\right) \\
& \quad \equiv \hat{p}_{i} f^{i}\left(x_{i}^{c}\right)-p^{f}\left(X^{c}\right) x_{i}^{c}-\hat{s}_{i}
\end{aligned}
$$$$
\text { s.t. }\left(p_{i}^{w}-\hat{p}_{i}\right) f^{i}\left(x_{i}^{c}\right)+\hat{s}_{i} \geq 0 \text {. }
$$

The optimal terms in the processor's contract specify that the retailer participation constraint be met with equality in (7), from which substitution results in the following unconstrained problem

$$
\begin{aligned}
& \underset{\hat{p}_{i}}{\operatorname{Max}} \pi_{i}\left(\hat{p}_{1}, \hat{p}_{2}\right) \\
& \quad \equiv p_{i}^{w} f^{i}\left(x_{i}^{c}\right)-p^{f}\left(X^{c}\right) x_{i}^{c}, \quad i=1,2 .
\end{aligned}
$$

Note in (8) that only the indirect effect of the contracted wholesale price remains; the direct effect of the contract price on the profitability of processor $i$ is exactly offset by the payment of the slotting allowance.

Differentiation of (8) with respect to $\hat{p}_{i}$ yields the necessary condition for a profitmaximizing contract

$$
\begin{aligned}
& \left(p_{i}^{w} f_{x}^{i}\left(x_{i}^{c}\right)-p^{f}\left(X^{c}\right)\right) \frac{\partial x_{i}^{c}}{\partial \hat{p}_{i}} \\
& -x_{i}^{c} p_{x}^{f}\left(X^{c}\right) \frac{\partial X^{c}}{\partial \hat{p}_{i}}=0, \quad i=1,2 .
\end{aligned}
$$

Proposition 1. The noncooperative Nash contract equilibrium for food processor $i, i=$ 1,2 , is characterized by

(i) a wholesale price above the noncontracted price; and

(ii) a positive slotting allowance.

Proof: Let $x_{i}^{*} \equiv x_{i}\left(\hat{p}_{1}^{*}, \hat{p}_{2}^{*}\right), \quad i=1,2$ denote the solution to the Nash equilibrium described by (9). To determine the equilibrium choice of $\hat{p}_{i}^{*}$, substitute the procurement stage solution (3) into (9), which gives

$$
\begin{aligned}
& \left(p_{i}^{w}-\hat{p}_{i}^{*}\right) f_{x}^{i}\left(x_{i}^{*}\right) \\
& \quad=x_{i}^{*} p_{x}^{f}\left(X^{*}\right) \frac{\partial x_{j}}{\partial x_{i}}\left(x_{j}^{*}, X^{*}\right)<0
\end{aligned}
$$

where the inequality holds by expression (6). Hence, the optimal contract of processor $i$ 
specifies a wholesale price above the noncontracted wholesale price for the processed good, $\hat{p}_{i}^{*}>p_{i}^{w}, i=1,2$.

To compensate the retailer for the higher expense of unit wholesale transactions, the contract specifies a positive lump-sum payment. The optimal level of this slotting allowance, $\hat{s}_{i}^{*}$, is identified by (7) as

$$
\hat{s}_{i}^{*}=\left(\hat{p}_{i}^{*}-p_{i}^{w}\right) f^{i}\left(x_{i}^{*}\right)>0, \quad i=1,2 .
$$

An oligopsonistic processor has an incentive to pay a slotting allowance to a retailer. By paying a slotting allowance to the retailer, the contracted processor is able to negotiate a higher wholesale price for the good, which, in turn, shifts the processor's marginal value product function outward relative to the rival processor in the farm product market. This shift increases the marginal profitability of procuring the farm product for the contracted processor. In total, of course, the direct contribution of the higher wholesale price to the processor's profit is exactly offset by the payment of the slotting allowance. Nonetheless, the outward shift in the marginal value product function alters the set of credible actions for the processor in her oligopsony rivalry for the farm product. A higher wholesale price purchased with a compensatory slotting allowance changes the reaction function of the contracted processor, thereby allowing her to commit to a higher procurement level that increases her oligopsony rent.

The formal structure of the slotting allowance as a precommitment mechanism is similar to the role of contracts in the vertical separation literature (see, e.g., Bonanno and Vickers, Lin, Coughlin and Wernerfelt, Shaffer, and Hamilton and Stiegert). A slotting allowance that supports a higher wholesale price is a commitment mechanism that creates an ex post beneficial expansion in a processor's level of farm product procurement. ${ }^{4}$ Through the use of this mechanism, the noncooperative oligopsony equilibrium is altered in favor of the contracted processor.

Because the processors face similar market incentives, the noncooperative Nash contract equilibrium is characterized by the multilateral use of slotting allowances. Nonetheless, the noncooperative Nash contract equilibrium

\footnotetext{
${ }^{4}$ It should be noted that if processors compete in prices instead of in quantities the optimal contract mechanism would involve a negative slotting allowance (a fee paid from the retailer to the food processor in exchange for a lower wholesale price). Such behavior would not be consistent with observed practice in wholesale markets.
}

is jointly suboptimal for the processors. The combined profit level of the two processors would be higher if slotting allowances were reduced below their Nash equilibrium levels. However, if one processor chose not to pay a slotting allowance, she could not deter her rival from paying a slotting allowance to secure a higher wholesale price. The noncontracting processor, in this case, would be worse off than if she had reciprocated with a slotting contract of her own.

\section{Producer Surplus Implications}

The noncooperative Nash contract equilibrium has the following implications for producer surplus.

Proposition 2. At the noncooperative Nash contract equilibrium:

(i) the joint profitability of food processors would increase if slotting allowances were reduced;

(ii) farm surplus would decrease if slotting allowances were reduced.

Proof: For part (i), note by (7) that the equilibrium level of the slotting allowance increases monotonically with the contract price. Therefore, it is sufficient to show that joint profitability of food processors would rise, and farm surplus would fall, in response to a decrease in the wholesale contract prices. The joint processor profit function is $\Pi\left(\hat{p}_{1}, \hat{p}_{2}\right)=$ $\pi^{1}\left(\hat{p}_{1}, \hat{p}_{2}\right)+\pi^{2}\left(\hat{p}_{1}, \hat{p}_{2}\right)$. Since $\frac{\partial \pi^{i}\left(\hat{p}_{1}, \hat{p}_{2}\right)}{\partial \hat{p}_{i}}=0$ at the noncooperative Nash equilibrium point, it follows that

$$
\begin{aligned}
& \frac{\partial \Pi\left(\hat{p}_{1}^{*}, \hat{p}_{2}^{*}\right)}{\partial \hat{p}_{i}} \\
& =\left(p_{j}^{w}-\hat{p}_{j}^{*}\right) f_{x}^{j}\left(x_{j}^{*}\right) \frac{\partial x_{j}^{c}\left(\hat{p}_{1}^{*}, \hat{p}_{2}^{*}\right)}{\partial \hat{p}_{i}} \\
& \quad-x_{j}^{*} p_{x}^{f}\left(X^{*}\right) \frac{\partial x_{i}^{c}\left(\hat{p}_{1}^{*}, \hat{p}_{2}^{*}\right)}{\partial \hat{p}_{i}} \quad i=1,2 .
\end{aligned}
$$

Substituting for $\left(P_{j}^{w}-\hat{p}_{j}^{*}\right) f_{x}^{j}\left(x_{j}^{*}\right)$ from (10) and gathering terms yields

$$
\begin{aligned}
& \frac{\partial \Pi\left(\hat{p}_{1}^{*}, \hat{p}_{2}^{*}\right)}{\partial \hat{p}_{i}}= x_{j}^{*} p_{x}^{f}\left(X^{*}\right) \frac{\partial x_{i}\left(\hat{p}_{1}^{*}, \hat{p}_{2}^{*}\right)}{\partial \hat{p}_{i}} \\
& \times\left[\left(\frac{\partial x_{i}}{\partial x_{j}}\left(x_{i}^{*}, X^{*}\right)\right)\right. \\
&\left.\times\left(\frac{\partial x_{j}}{\partial x_{i}}\left(x_{j}^{*}, X^{*}\right)\right)-1\right] \\
& i=1,2
\end{aligned}
$$


which is negative by (1), (4), and (6). Hence, a reduction in $\hat{p}_{i}^{*}, i=1,2$, increases the joint profitability of food processors.

For part (ii), farm surplus at the noncooperative Nash equilibrium point is given by

$$
G\left(\hat{p}_{1}^{*}, \hat{p}_{2}^{*}\right)=p^{f}\left(X^{*}\right) X^{*}-\int_{0}^{X^{*}} p^{f}(z) d z
$$

It follows that

$$
\begin{array}{r}
\frac{\partial G\left(\hat{p}_{1}^{*}, \hat{p}_{2}^{*}\right)}{\partial \hat{p}_{i}}=p_{x}^{f}\left(X^{*}\right) X^{*}\left(\frac{\partial X\left(\hat{p}_{1}^{*}, \hat{p}_{2}^{*}\right)}{\partial \hat{p}_{i}}\right) \\
i=1,2
\end{array}
$$

which is positive by (1), (4), and (5). Hence, a reduction in $\hat{p}_{i}^{*}, i=1,2$, decreases farm surplus.

Relative to a vertical market system without slotting allowances, the noncooperative Nash contract equilibrium is associated with a larger level of farm surplus. The higher wholesale price negotiated by each food processor in the slotting contract increases the total level of farm product procurement, and this correspondingly increases the equilibrium farm price.

The effect of slotting allowances on (total) producer surplus sums the gain in farm surplus and the loss in processor surplus. Figure 2 demonstrates the effect of a unilateral slotting contract on producer surplus.
The figure depicts the special case of linear farm supply, homogeneous processed products, and fixed proportions processing technology given by $f^{i}\left(x_{i}\right)=x_{i}$, for $i=1,2$. In the figure, $p_{R}^{f, n}\left(x_{1}^{n}\right)=p_{R}^{f, n}\left(X^{n}-x_{2}^{n}\right)$ and $p_{R}^{f, c}\left(x_{1}^{c}\right)=$ $p_{R}^{f, c}\left(X^{c}-x_{2}^{c}\right)$ denote the (inverse) residual farm supply function facing processor 1 in the noncontracted and contracted case, respectively. The residual supply function is obtained in each case by shifting the farm supply function to the left (by either $x_{2}^{n}$ or $x_{2}^{c}$ units). The slotting contract of processor 1 decreases the equilibrium level of farm product procurement by processor 2 in (5), which is represented in the figure by the outward shift in residual supply in the contracted case. The marginal outlay schedule corresponding to each residual farm supply function defines processor 1's reaction function in each case, and this is denoted in the figure by $R_{1}^{n}\left(x_{2}^{n}\right)$ in the noncontracted case and by $R_{1}^{c}\left(x_{2}^{c}\right)$ in the contracted case.

Consider, first, the benchmark social optimum. This situation is depicted by the surplusmaximizing market quantity, $X^{s}$, which is where the farm supply function, $p^{f}(X)$, equates with the noncontracted wholesale product price of the homogeneous processed good, $p^{w}$. Next, consider the baseline oligopsony outcome in the noncontracted case. Without a slotting contract, the equilibrium level of farm product use for processor $1, x_{1}^{0}$, is determined by the intersection of the noncontracted

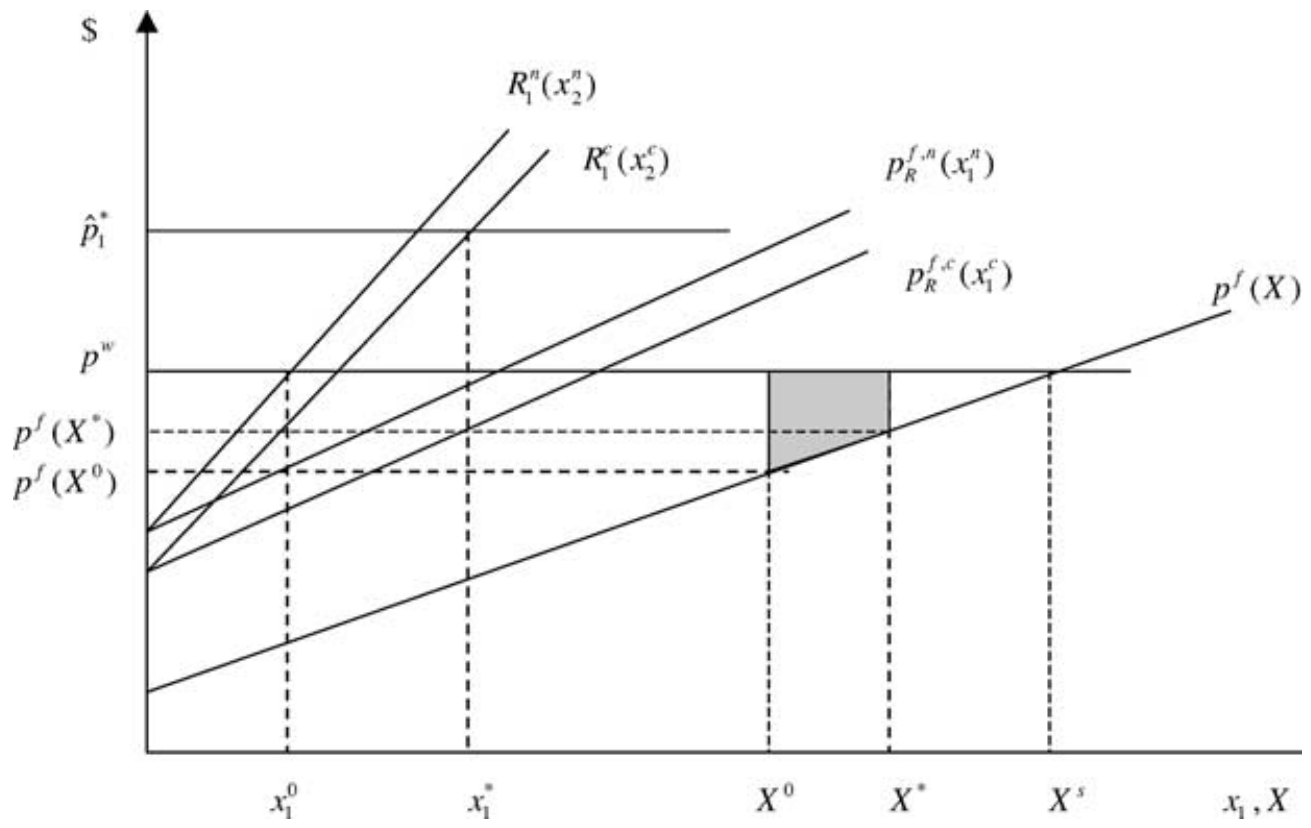

Figure 2. Residual farm supply and the producer surplus implications of slotting allowances 
marginal outlay schedule, $R_{1}^{n}\left(x_{2}^{n}\right)$, with the wholesale price, $p^{w}$. At this quantity, the equilibrium farm price is identified by the residual supply function as $p^{f}\left(X^{0}\right)=p_{R}^{f, n}\left(x_{1}^{0}\right)$, which results in a total level of farm product procurement of $X^{0}$.

Now consider the outcome under a slotting allowance. A slotting contract by processor 1 results in the two effects shown in the figure: (a) processor 1's contract specifies a relatively higher wholesale price, $\hat{p}_{1}^{*}>p^{w}$; and $(b)$ the higher wholesale price, in turn, shifts processor 1 's reaction function outward from $R_{1}^{n}\left(x_{2}^{n}\right)$ to $R_{1}^{c}\left(x_{2}^{c}\right)$. The equilibrium level of farm product use by processor 1 in the contracted case, $x_{1}^{*}$, is now determined by the intersection of $R_{1}^{c}\left(x_{2}^{c}\right)$ with the contract price, $\hat{p}_{1}^{*}$, which results in an equilibrium farm price of $p^{f}\left(X^{*}\right)=p_{R}^{f, c}\left(x_{1}^{*}\right)$ and a total level of farm product procurement given by $X^{*}$. Ignoring distributional considerations, the total increase in producer surplus (farmers plus food processors) under the slotting allowance is represented by the shaded region of the figure.

A unilateral slotting allowance generally increases producer surplus in the food system. Nonetheless, it is possible for a unilateral slotting allowance to decrease producer surplus under circumstances in which the processing technology differs across firms. To see this, suppose processor 2 is the more cost-efficient food processor in the sense that $f_{x}^{2}(\bar{x})>f_{x}^{1}(\bar{x})$ and $f_{x x}^{2}(\bar{x}) \geq f_{x x}^{1}(\bar{x})$ for all $\bar{x}$. In this case, a slotting contract by processor 1 produces two countervailing effects on producer surplus. The total procurement level of the farm product increases, which increases producer surplus, but, at the same time, production in the processing sector is redistributed from the low-cost processor to the relatively high-cost processor, which reduces allocative efficiency. In the case depicted in figure 2, this latter redistributive effect has no welfare consequence because the processors are assumed to have symmetric, fixed proportions processing technology. If the food processors have asymmetric costs, then it is conceivable that a unilateral slotting allowance by the relatively cost-inefficient processor reduces total producer surplus.

Of course, the noncooperative Nash contract equilibrium is characterized by multilateral slotting allowances. Under multilateral slotting allowances, allocative efficiency in the processing sector is reduced by the contract of the relatively cost-inefficient processor, but increased by the contract of the relatively cost- efficient processor. In equilibrium, the combined effect of slotting allowances on allocative efficiency is of second-order significance in the producer surplus calculation. To clarify the effect of slotting allowances on producer surplus in the noncooperative Nash contract equilibrium, it is helpful to suppress the offsetting effects of the slotting contracts on allocative efficiency. To do this, consider the case of symmetric food processors, $f^{i}(\cdot)=f(\cdot), i=1,2$.

Proposition 3. At the noncooperative Nash contract equilibrium with symmetric food processors, the combined producer surplus of farmers and food processors would fall if slotting allowances were reduced.

Proof: Producer surplus in the vertical system is $S\left(\hat{p}_{1}, \hat{p}_{2}\right)=\Pi\left(\hat{p}_{1}, \hat{p}_{2}\right)+G\left(\hat{p}_{1}, \hat{p}_{2}\right)$. At the noncooperative Nash equilibrium point, the effect of a change in the wholesale price of processor $i$ on producer surplus is given by the sum of effects in (12) and (13). Combining these expressions yields

$$
\begin{aligned}
\frac{\partial S\left(\hat{p}_{1}^{*}, \hat{p}_{2}^{*}\right)}{\partial \hat{p}_{i}}= & p_{x}^{f}\left(X^{*}\right) \frac{\partial x_{i}\left(\hat{p}_{1}^{*}, \hat{p}_{2}^{*}\right)}{\partial \hat{p}_{i}} \\
& \times\left[x_{i}^{*}\left(1+\frac{\partial x_{j}}{\partial x_{i}}\left(x_{j}^{*}, X^{*}\right)\right)\right. \\
& +x_{j}^{*} \frac{\partial x_{j}}{\partial x_{i}}\left(x_{j}^{*}, X^{*}\right) \\
& \left.\times\left(1+\frac{\partial x_{i}}{\partial x_{j}}\left(x_{i}^{*}, X^{*}\right)\right)\right]
\end{aligned}
$$

Next, let $x_{i}^{*}=x^{*}, i=1,2$, denote the level of farm product procurement by each processor in a symmetric oligopsony configuration, and notice that $\frac{\partial x_{i}}{\partial x_{j}}\left(x_{i}^{*}, X^{*}\right)=\frac{\partial x_{j}}{\partial x_{i}}\left(x_{j}^{*}, X^{*}\right)$ in the symmetric case. This implies

$$
\begin{aligned}
\frac{\partial S\left(\hat{p}_{1}^{*}, \hat{p}_{2}^{*}\right)}{\partial \hat{p}_{i}}= & x^{*} p_{x}^{f}\left(X^{*}\right) \frac{\partial x_{i}\left(\hat{p}_{1}^{*}, \hat{p}_{2}^{*}\right)}{\partial \hat{p}_{i}} \\
& \times\left(1+\frac{\partial x_{j}}{\partial x_{i}}\left(x_{j}^{*}, X^{*}\right)\right)^{2}
\end{aligned}
$$

which is positive by (4).

Slotting allowances increase producer surplus in the food system. Relative to the case of wholesale grocery transactions that do not involve slotting allowances, the joint profitability of food processors is lower, but the level of farm surplus is higher and more than compensates for the loss in processor surplus. 
The market equilibrium that supports each of the results above is subgame perfect. Nonetheless, in dynamic processor games it is possible that trigger strategies could be employed to support an outcome that increases processor profits. The collusive outcome can be analyzed as follows. Let $x_{i}^{m}=x_{i}\left(\hat{p}_{1}^{m}, \hat{p}_{2}^{m}\right), i=$ 1,2 , denote the joint profit-maximizing procurement levels of the farm product, where $\hat{p}_{i}^{m}$ are the joint profit-maximizing wholesale prices. The solution to the cooperative profit maximization problem provides the following result.

PROPOSITION 4. The cooperative solution that maximizes joint processor profit is characterized by negative slotting allowances.

Proof: At the jointly optimal solution, $\frac{\partial \Pi\left(\hat{p}_{1}^{m}, \hat{p}_{2}^{m}\right)}{\partial \hat{p}_{i}}=0, i=1,2$, where

$$
\begin{aligned}
\frac{\partial \Pi\left(\hat{p}_{1}, \hat{p}_{2}\right)}{\partial \hat{p}_{i}}= & \frac{\partial \pi^{1}\left(\hat{p}_{1}, \hat{p}_{2}\right)}{\partial \hat{p}_{i}} \\
& +\frac{\partial \pi^{2}\left(\hat{p}_{1}, \hat{p}_{2}\right)}{\partial \hat{p}_{i}} .
\end{aligned}
$$

Making use of (3), the joint optimum simultaneously solves

$$
\begin{aligned}
& {\left[\left(p_{1}^{w}-\hat{p}_{1}\right) f_{x}^{1}\left(x_{1}^{c}\right)-x_{1}^{c} p_{x}^{f}\left(X^{c}\right)\right] \frac{\partial x_{1}^{c}}{\partial \hat{p}_{1}}} \\
& \quad+\left[\left(p_{2}^{w}-\hat{p}_{2}\right) f_{x}^{2}\left(x_{2}^{c}\right)-x_{2}^{c} p_{x}^{f}\left(X^{c}\right)\right] \\
& \quad \times \frac{\partial x_{2}^{c}}{\partial \hat{p}_{1}}=0
\end{aligned}
$$

and

$$
\begin{aligned}
& {\left[\left(p_{1}^{w}-\hat{p}_{1}\right) f_{x}^{1}\left(x_{1}^{c}\right)-x_{1}^{c} p_{x}^{f}\left(X^{c}\right)\right] \frac{\partial x_{1}^{c}}{\partial \hat{p}_{2}}} \\
& \quad+\left[\left(p_{2}^{w}-\hat{p}_{2}\right) f_{x}^{2}\left(x_{2}^{c}\right)-x_{2}^{c} p_{x}^{f}\left(X^{c}\right)\right] \\
& \quad \times \frac{\partial x_{2}^{c}}{\partial \hat{p}_{2}}=0 .
\end{aligned}
$$

By inspection of (14) and (15), the unique solution to this problem is

$$
p_{i}^{w}-\hat{p}_{i}^{m}=\frac{x_{i}^{m} p_{x}^{f}\left(X^{m}\right)}{f_{x}^{i}\left(x_{i}^{m}\right)}>0
$$

for $i=1,2$.

Thus, the joint profit-maximizing contract prices are set below the noncontracted wholesale prices. Accordingly, the levels of the slot- ting fees that maximize joint processor profit follow from (7) as

$$
\begin{aligned}
\hat{s}_{i}^{m}=-x_{i}^{m} p_{x}^{f}\left(X^{m}\right) \frac{f^{i}\left(x_{i}^{m}\right)}{f_{x}^{i}\left(x_{i}^{m}\right)} & <0 \\
& \text { for } i=1,2 .
\end{aligned}
$$

In a collusive situation, the processors maximize joint profit by establishing contract terms with retailers that stipulate negative slotting allowances in exchange for lower wholesale prices. A wholesale price reduction shifts the marginal value product function downward for each processor in the farm product market, which reduces procurement levels and decreases farm prices to the monopsony level that maximizes joint processor profit. Consistent with this outcome, it is interesting to note that, in some cases, large food processors have made public claims not to pay slotting allowances. $^{5}$

\section{Extension to the Retail Market}

Thus far, the analysis has suppressed an important element of the food system: the market contact between a grocery retailer and his consumers. The goal of this section is to formally connect the model to the downstream retail market. The analysis proceeds in two portions. In the first portion, a single myopic retailer is considered who does not anticipate the effect of the slotting allowance on retail prices. This situation produces an equivalent contracting environment to that which obtained previously under perfect retail competition. The noncooperative Nash contract equilibrium is extended in this framework to examine the effect of slotting allowances on retail prices and consumer welfare. In the second portion, nonmyopic retailer behavior is considered and conditions are derived under which processor-motivated slotting allowances continue to emerge in the noncooperative Nash contract equilibrium.

The retail sector is framed in a highly stylized fashion. A single grocery retailer purchases a set of differentiated wholesale products, provides shelf space for them, and then sells them to consumers in a retail market. Let $p_{i}^{r}(Y)$ denote the inverse demand for product $i$ in the retail market, where $Y$ is a vector of all retail goods, some of which may be substitutes and

\footnotetext{
${ }^{5}$ A notable example is Proctor \& Gamble.
} 
some of which may be complements to processed good $i$. A nonempty subset of $Y$ contains processed goods produced by rival food processors that compete to procure a farm product in an oligopsony market common to processor $i$. Suppose for analytic convenience that the retailer stocks a single product for each of two processors, so that the vector of retail goods can be written as $Y=\left(y_{1}, y_{2}\right)$. All other arguments that influence retail prices are suppressed.

It is interesting to note that the possibility exists for oligopsony food processors to purchase a homogeneous farm product in a common upstream market, but sell complementary processed goods in the wholesale market (e.g., corn tortillas and margarine). In the analysis to follow, attention is centered on the more common case in which food processors produce and sell differentiated substitute goods. ${ }^{6}$

The retail (inverse) demand functions for processed products are assumed to be differentiable and satisfy

$$
\begin{aligned}
& \frac{\partial p_{i}^{r}(Y)}{\partial y_{i}}<0, \quad \frac{\partial p_{i}^{r}(Y)}{\partial y_{j}}<0, \quad \text { and } \\
& \left|\frac{\partial p_{i}^{r}(Y)}{\partial y_{i}}\right| \geq\left|\frac{\partial p_{i}^{r}(Y)}{\partial y_{j}}\right| .
\end{aligned}
$$

These conditions, respectively, ensure that inverse demand for each retail good slopes downward, that the products are substitutes, and that, on the margin, a change in a processor's own-quantity has a (at least weakly) greater effect on the price of her retail good than a change in the rival processor's quantity. This latter condition in (16) is met with equality in the case of homogeneous retail products; otherwise, the inequality holds strictly.

To establish the effect of a slotting allowance by food processor $i$ on retail prices, assume the retailer does not hold an inventory. In this case, the quantity vector that clears the retail market also clears the farm product market. Let $Y^{c}=\left(f^{i}\left(x_{i}^{c}\right), f^{j}\left(x_{j}^{c}\right)\right)$ denote this retail quantity vector. Accordingly, the retail price effects of a slotting allowance by processor $i$ are

$$
\begin{aligned}
\frac{\partial p_{i}^{r}\left(Y^{c}\right)}{\partial \hat{p}_{i}}= & \frac{\partial p_{i}^{r}\left(Y^{c}\right)}{\partial y_{i}^{c}} f_{x}^{i}\left(x_{i}^{c}\right) \frac{\partial x_{i}^{c}}{\partial \hat{p}_{i}} \\
& +\frac{\partial p_{i}^{r}\left(Y^{c}\right)}{\partial y_{j}^{c}} f_{x}^{j}\left(x_{j}^{c}\right) \frac{\partial x_{j}^{c}}{\partial \hat{p}_{i}}<0
\end{aligned}
$$

\footnotetext{
${ }^{6}$ The qualitative predictions of the model are similar for the case in which retailers produce complementary goods. Details are available from the author upon request.
}

and

$$
\begin{aligned}
\frac{\partial p_{j}^{r}\left(Y^{c}\right)}{\partial \hat{p}_{i}}= & \frac{\partial p_{j}^{r}\left(Y^{c}\right)}{\partial y_{i}^{c}} f_{x}^{i}\left(x_{i}^{c}\right) \frac{\partial x_{i}^{c}}{\partial \hat{p}_{i}} \\
& +\frac{\partial p_{j}^{r}\left(Y^{c}\right)}{\partial y_{j}^{c}} f_{x}^{j}\left(x_{j}^{c}\right) \frac{\partial x_{j}^{c}}{\partial \hat{p}_{i}}
\end{aligned}
$$

in markets $i$ and $j$, respectively. Expressions (17) and (18) decompose the retail price effect for each good into own- and cross-effects on (inverse) demand weighted by the magnitudes of the quantity changes. In (17), the first term is the direct effect of processor $i$ 's slotting contract on the retail price of her own processed good, which is negative by (4) and (16). The second term is the indirect effect of processor $i$ 's slotting contract on her retail price that obtains from the output reduction of rival processor $j$. This term is positive because goods $i$ and $j$ are substitutes; however, given the relative magnitude of the output effects in (4) and (5), the indirect effect is guaranteed to be smaller in magnitude than the direct effect by (16). This implies that the sum of effects in (17) is negative. In (18), a slotting allowance by processor $i$ has two effects on the retail price of rival good $j$ : processor $i$ 's contract increases the output of processor $i$, which has a negative cross-effect on the price of good $j$, but processor $i$ 's contract also reduces the output of processor $j$, which has a positive (direct) effect on the price of good $j$. The sum of these effects takes an ambiguous sign because the quantity adjustment by processor $i$ in response to her slotting allowance is larger (in absolute value) than the quantity adjustment of processor $j$. For homogeneous processed goods, a slotting allowance by processor $i$ unambiguously decreases the retail price. For sufficiently differentiated processed goods, the retail price of good $j$ increases in response to a slotting allowance by processor $i$.

The retail price effect in (17) has two immediate implications that deserve further emphasis. First, a slotting contract by processor $i$ decreases the retail margin on processed good $i$ from the noncontracted level. A slotting contract that increases the wholesale price of processor $i$ above the noncontracted level decreases the retail price of good $i$ in (17), and this squeezes the retail margin from both sides. Second, the consumer surplus implication of a slotting allowance is immediate from (17). A contract that increases the wholesale price of processed good $i$ lowers the retail price consumers pay for good $i$, which unambiguously 
increases consumer surplus in the market for $\operatorname{good} i$.

A unilateral slotting contract by processor $i$ influences the retail price of both processed goods. This implies that the total effect on consumer utility is determined jointly by the price effects in (17) and (18). To construct a utilitybased measure for these effects, suppose differences across individual consumers are limited to those which permit equilibrium prices and outputs to be determined by an aggregate utility function. Let $V\left(y_{1}^{*}\left(\hat{p}_{1}, \hat{p}_{2}\right), y_{2}^{*}\left(\hat{p}_{1}, \hat{p}_{2}\right)\right)$ denote the corresponding indirect utility function. Next, evaluate this function at the noncooperative Nash equilibrium point and perturb the contract price of processor $i$. Making use of the envelope theorem, this gives

$$
\begin{aligned}
& \frac{\partial V\left(\hat{p}_{1}^{*}, \hat{p}_{2}^{*}\right)}{\partial \hat{p}_{i}} \\
& =-\lambda^{*}\left[y_{i}^{*} \frac{\partial p_{i}^{r}\left(Y^{*}\right)}{\partial \hat{p}_{i}}+y_{j}^{*} \frac{\partial p_{j}^{r}\left(Y^{*}\right)}{\partial \hat{p}_{i}}\right], \\
& i=1,2
\end{aligned}
$$

where $\lambda^{*}>0$ is the marginal utility of income. Equation (19) measures the change in consumer welfare in terms of the equivalent variation. If the quantity-weighted sum of price effects in the square brackets of (19) is positive, then a slotting contract that increases the wholesale price of processed good $i$ increases the expenditure level necessary to procure the original consumption bundle. Utility decreases in this case by implication.

The qualitative effect of a unilateral slotting contract on consumer welfare depends on the degree of product differentiation in the retail market. In the case of homogeneous retail products, both price effects are negative in (19) and it follows that consumer welfare unambiguously increases in response to a slotting allowance by processor $i$. In the case of differentiated retail products, the sum of price effects in (19) is ambiguous and it is conceivable that a unilateral slotting contract by processor $i$ reduces consumer welfare. Such a perverse outcome for consumer welfare can only occur, however, when the retail products are sufficiently differentiated and when the unilateral slotting contract is negotiated for the processed good which is relatively less desirable in consumption.

Under multilateral contracts, slotting allowances have clear implications for consumer welfare under symmetric market conditions. To see this, consider the case in which the food processors have identical production technology and produce processed goods that are symmetric substitutes in the sense of Dixit and Stiglitz. $^{7}$

Proposition 5. At a noncooperative Nash contract equilibrium with symmetric food processors, consumer welfare would decrease if slotting allowances were reduced.

Proof: Let $x_{i}^{*}=x^{*}$, and $y_{i}^{*}=y^{*}, i=1,2$, denote the equilibrium level of farm product use and output by each processor in a symmetric market configuration. Making use of these conditions and the symmetry of the retail price effects, $\partial p_{i}^{r}\left(Y^{*}\right) / \partial y_{i}=\partial p_{j}^{r}\left(Y^{*}\right) / \partial y_{j}$ and $\partial p_{i}^{r}\left(Y^{*}\right) / \partial y_{j}=\partial p_{j}^{r}\left(Y^{*}\right) / \partial y_{i}$, substitution of (17) and (18) into (19) yields

$$
\begin{aligned}
& \frac{\partial V\left(\hat{p}_{1}^{*}, \hat{p}_{2}^{*}\right)}{\partial \hat{p}_{i}} \\
& =-\lambda^{*}\left[y^{*} f_{x}^{i}\left(x^{*}\right) \frac{\partial x_{i}^{*}\left(\hat{p}_{1}^{*}, \hat{p}_{2}^{*}\right)}{\partial \hat{p}_{i}^{*}}\right. \\
& \quad \times\left(\frac{\partial p_{i}^{r}\left(Y^{*}\right)}{\partial y_{i}}+\frac{\partial p_{i}^{r}\left(Y^{*}\right)}{\partial y_{j}}\right) \\
& \left.\quad \times\left(1+\frac{\partial x_{j}}{\partial x_{i}}\left(x_{j}^{*}, X^{*}\right)\right)\right]>0, \\
& \quad i=1,2
\end{aligned}
$$

where the inequality holds by (1), (4), and (6). Slotting allowances reduce retail prices and increase consumer welfare.

Thus far, the retailer has been assumed to be myopic. Under nonmyopic retailer behavior, it remains to be demonstrated that a set of retail market conditions exist in which slotting allowances emerge in the noncooperative Nash contract equilibrium. To assess the type of retail market conditions that support slotting allowances as an equilibrium outcome, it is sufficient to identify the circumstances under which processor incentives exist to increase wholesale prices from their noncontracted levels in a two-part tariff structure.

When the retailer is not myopic, slotting allowances must compensate the retailer for the effect of the contracted wholesale prices on

\footnotetext{
${ }^{7}$ Retail goods in the symmetric substitutes model are allowed to be highly differentiated, but are viewed to be equally desirable to consumers at equal retail prices. This would be the case, for example, when consumers are uniformly distributed in the characteristic-space that differentiates the two goods.
} 
the equilibrium retail prices. The level of compensation necessary to induce the retailer to accept a contract depends on various features that characterize the solution to the retailer's problem. The nature of the problem facing a multi-product retailer is interesting and important in its own right; however, to maintain the present focus on food processor incentives, the retailer's problem is framed with a minimal amount of structural detail.

Consider a retailer who faces constant marginal cost of $\$ c$ per unit for each good that is stocked on his shelf. The retailer incurs positive fixed costs for providing shelf space to the processed goods. Suppose a solution exists to the retailer's problem. At an initial position without slotting contracts, this solution can be characterized by an arbitrary level of equilibrium retail profit on each good denoted by

$$
\begin{aligned}
M_{i}^{0} & \equiv \pi_{i}^{r}\left(y_{i}^{0}, Y^{0}, p_{i}^{w}\right) \\
& =\left(p_{i}^{r}\left(Y^{0}\right)-p_{i}^{w}\right) y_{i}^{0}, \quad i=1,2
\end{aligned}
$$

where $M_{i}^{0}$ is the retailer's marketing return (or quasi-rent) on processed $\operatorname{good} i$ and $Y^{0}=$ $\left(y_{1}^{0}, y_{2}^{0}\right)$ is the vector of equilibrium retail quantities that coincides with the initial noncontracted wholesale prices, $\hat{p}_{i}=p_{i}^{w}$ and $\hat{s}_{i}=0$, $i=1$, 2. Marginal cost, which is constant, can be subsumed into retail demand without loss of generality.

The retail market outcome in (21) can be given several interpretations. For example, the retailer's problem might be specified in the context of a Ramsey optimization problem, in which case the sum of marketing returns across products would recover supermarket fixed costs at retail prices that minimize deadweight loss (see, e.g., Baumol and Bradford). Alternatively, the retailer's problem might be one of multi-product retail monopoly (or oligopoly), in which case the retail margin on each product would be set to equalize marginal marketing returns across products.

Given the solution to the retailer's problem (21), suppose the retailer is willing to accept a contract proposed by processor $i$ whenever the slotting allowance provides a return in the retail market that (at least weakly) exceeds his existing marketing return on processed good $i{ }^{8}$ That is, the retailer accepts processor $i$ 's con-

\footnotetext{
${ }^{8}$ This specification of the retailer participation constraint, which compensates the retailer only for the effect of a slotting allowance on the marketing return of retail good $i$, and not for its indirect effect on the marketing return of retail good $j$, might be thought
}

tract whenever

$$
\left(p_{i}^{r}\left(Y^{c}\right)-\hat{p}_{i}\right) y_{i}^{c}+\hat{s}_{i} \geq M_{i}^{0}, \quad i=1,2
$$

and otherwise rejects it.

Processor $i$, in turn, chooses the terms of her slotting contract to maximize profits in (2) subject to the participation constraint (22) and the procurement stage solutions. Specifically, the contracting problem facing processor $i$ is

$$
\begin{array}{cc}
\operatorname{Max}_{\hat{p}_{i}, \hat{s}_{i}} & \hat{p}_{i} f^{i}\left(x_{i}^{c}\right)-p^{f}\left(X^{c}\right) x_{i}^{c}-\hat{s}_{i} \\
\text { s.t. } & \left(p_{i}^{r}\left(Y^{c}\right)-\hat{p}_{i}\right) f^{i}\left(x_{i}^{c}\right)+\hat{s}_{i} \\
& -\left(p_{i}^{r}\left(Y^{0}\right)-p_{i}^{w}\right) y_{i}^{0} \geq 0 .
\end{array}
$$

Noting that the optimal processor contract meets the participation constraint with equality, this expression can be differentiated with respect to $\hat{p}_{i}$ to obtain

$$
\begin{aligned}
& \frac{d \pi_{i}\left(\hat{p}_{1}, \hat{p}_{2}\right)}{d \hat{p}_{i}} \\
& =f^{i}\left(x_{i}^{c}\right) \frac{\partial p_{i}^{r}\left(Y^{c}\right)}{\partial \hat{p}_{i}} \\
& \quad+\left(p_{i}^{r} f_{x}^{i}\left(x_{i}^{c}\right)-p^{f}\left(X^{c}\right)\right) \frac{\partial x_{i}^{c}}{\partial \hat{p}_{i}} \\
& \quad-x_{i}^{c} p_{x}^{f}\left(X^{c}\right) \frac{\partial X^{c}}{\partial \hat{p}_{i}}, \quad i=1,2 .
\end{aligned}
$$

A contract that specifies a positive slotting allowance in exchange for a higher wholesale price increases the profit of processor $i$ whenever the sum of the three terms in expression (23) is positive. The retail market features that support slotting allowances as a processormotivated outcome can be summarized from this equation as follows.

Proposition 6. A food processor's incentive to pay a slotting allowance increases with:

(i) the elasticity of retail demand for her product;

(ii) the size of the retail margin on her product;

(iii) the degree of oligopsony power in the farm product market.

of as "fend-for-yourself" marketing. In a setting of multilateral contracts, each processor simultaneously writes a slotting contract to compensate the retailer for the marketing return on her own product. Alternatively, one could consider a retailer that demands "full compensation" from processor $i$ for the effect of her slotting allowance on the marketing return on both retail goods $i$ and $j$. This view may accord well in a setting of unilateral contracts. Details in the "full compensation" case are available from the author upon request. 
Proof: Substituting the procurement stage solutions (3) into (23) and evaluating this expression at the noncontracted wholesale price position (i.e., $x_{i}=x_{i}^{0}, y_{i}=y_{i}^{0}, \hat{p}_{i}^{0}=p_{i}^{w}$, and $\hat{s}_{i}^{0}=$ $0)$, processor $i$ has an incentive to pay a positive slotting allowance whenever

$$
\begin{aligned}
& y_{i}^{0} \frac{\partial p_{i}^{r}\left(Y^{0}\right)}{\partial \hat{p}_{i}}+\left(p_{i}^{r}\left(Y^{0}\right)-p_{i}^{w}\right) \\
& \times f_{x}^{i}\left(x_{i}^{0}\right) \frac{\partial x_{i}^{c}\left(\hat{p}_{1}^{0}, \hat{p}_{2}^{0}\right)}{\partial \hat{p}_{i}} \\
& -x_{i}^{0} p_{x}^{f}\left(X^{0}\right) \frac{\partial x_{j}^{c}\left(\hat{p}_{1}^{0}, \hat{p}_{2}^{0}\right)}{\partial \hat{p}_{i}}>0 .
\end{aligned}
$$

The first term in (24) is the retail price effect of processor $i$ 's slotting allowance. This term is negative by (17). A slotting contract by processor $i$ reduces the retail price of good $i$, which increases the level of compensation she must pay in the lump-sum component to meet the retailer participation constraint (22). The retail price effect reduces the profitability of the contract to processor $i$ in proportion to the initial quantity sold in the retail market, $y_{i}^{0}$. In terms of the retail demand elasticity, the crosseffect of a quantity change on the price of good $i$ is bounded by the own-effect in (16) and it follows that processor $i$ 's incentive to propose a slotting allowance increases with the magnitude of the (direct) elasticity of demand for retail good $i$.

The second term is the retail margin effect. This term is positive. A slotting contract by processor $i$ increases the output of $\operatorname{good} i$, which increases the retailer's rent in proportion to the size of the existing retail margin. The increase in retail rent correspondingly reduces the compensation necessary to meet the participation constraint in (22) and makes a slotting allowance more attractive for processor $i$.

The final term in (24) is the oligopsony incentive for a slotting allowance. A slotting allowance by processor $i$ reduces the procurement level of the rival processor in the farm product market, which shifts oligopsony rent to firm $i$. This term is positive and has a magnitude that increases as the farm supply function becomes more inelastic.

\section{Discussion and Empirical Implications}

Is the observed pattern of the slotting allowances in the wholesale grocery market consistent with the contract design problem of food processing firms? This section presents and interprets some underlying characteristics and general trends in the U.S. food system under the lens of the theory.

Several trends in the U.S. food system are consistent with favorable changes in processor incentives at the time slotting allowances emerged in 1984. In the 1961-86 period, Sullivan finds that the gross retail margin across all grocery products increased in U.S. supermarkets. To the extent that retail margins also increased for the subset of processed goods, this would increase processor incentives for slotting allowances. It is also widely recognized that the period surrounding the emergence of slotting allowances was characterized by considerable technological change in the farm sector. Technological change in the farm sector tends to reduce variable costs and increase fixed costs (e.g., by replacing farm labor with capital equipment), so that the adoption of modern technology in this period may have made farm supply functions less elastic and increased oligopsony power. ${ }^{9}$ Finally, this period also coincides with the trend toward highly differentiated retail products in the food system. Product differentiation in the retail food market provides consumers with a more refined set of product choices, which is likely to increase the elasticity of retail demand facing individual processed goods. These trends in the food system are consistent with an increase in processor incentives for slotting allowances.

The empirical footprint of a slotting allowance under food processor incentives differs in some important ways from that which would be left under an alternative theory. A unique feature of the present model is that it generates potentially refutable hypotheses regarding the subset of products for which processor incentives emerge for two-part tariffs. Two observations follow immediately from this point. First, a necessary condition for a processor incentive to exist is a degree of multimarket contact at the upstream and wholesale levels of the food system. A farmer who sells a farm product directly to a retailer in the wholesale market can have no incentive of this form. This observation provides a testable prediction to explain why slotting allowances are common in processed product categories, but not in other product categories such as fresh produce and in-store bakery products where there is no element of market intermediation between the farm product and wholesale markets. Second,

\footnotetext{
${ }^{9}$ This point was first made by Just and Chern regarding the adoption of the mechanized tomato harvester in California.
} 


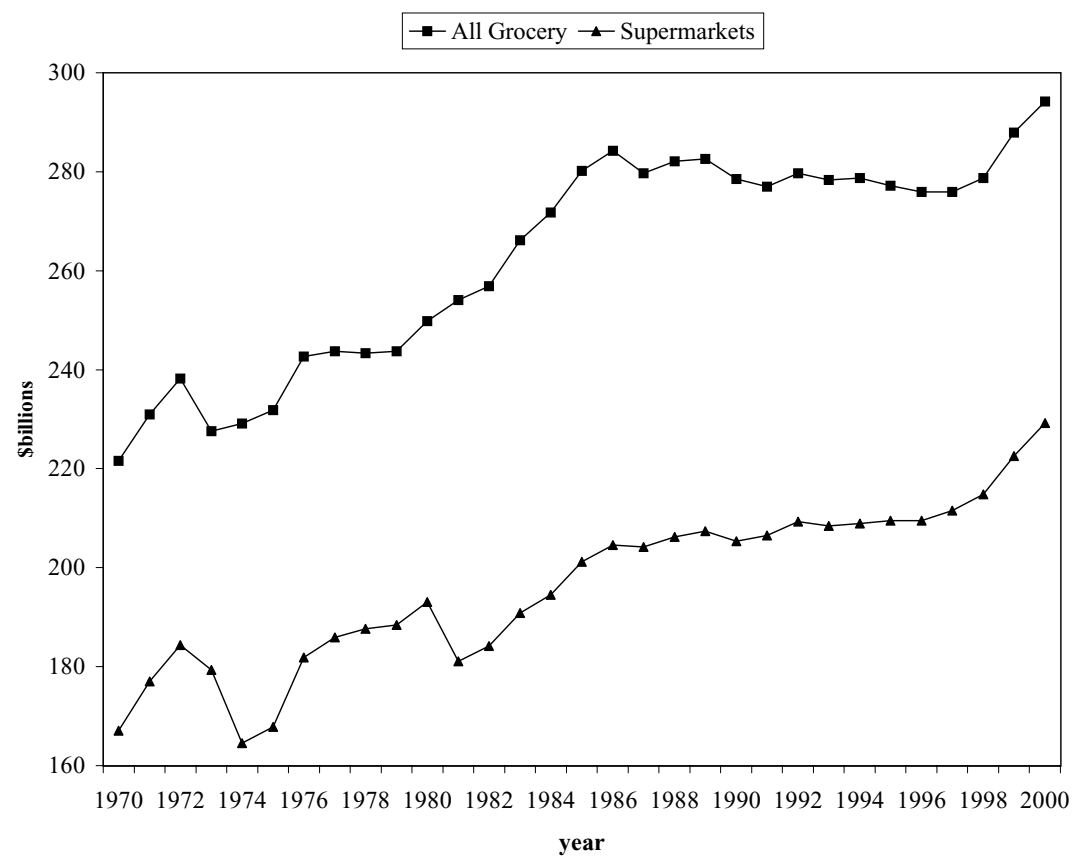

Source: Progressive Grocer

\section{Figure 3. Annual grocery sales in billions of 1982-84 dollars}

given that this necessary condition is met, the model outlines a number of sufficient conditions for food processor incentives to exist. For example, a slotting contract is most attractive in vertical markets with a high degree of retail competition and a large degree of oligopsony power in the farm product market.

Is the theory of processor-driven slotting allowances consistent with observed practices in the supermarket? Unfortunately, negotiations for slotting allowances are often made orally and in private; hence public data on individual transactions are virtually nonexistent. Nonetheless, the theory developed here suggests an interpretation of aggregate supermarket data based on several industry trends. In particular, critical differences between the present theory and existing models of slotting allowances are stratified in two dimensions of the data: (a) through time trends in the level of supermarket prices, quantities and profits, and $(b)$ through cross-sectional comparisons of gross retail margins in product categories with and without slotting allowances.

The retail market features that develop through processor incentives for slotting allowances contrast sharply with the profile that emerges when retailers employ two-part tariffs to exercise market power. In Shaffer's theory of retailer-mandated fees, for instance, the lens on slotting allowances is reversed in the sense that food processors (and not retailers) are driven down to their reservation profit levels by the contracts. Positive slotting allowances and higher wholesale prices obtain identically under forces of retail market power; however, the implication of the fees for market performance is exactly opposite to that described here. ${ }^{10}$ Under retail oligopoly, slotting allowances increase retailer profit only to the extent that higher wholesale prices support higher retail prices, and this implies that the total quantity of retail grocery sales must decrease. It is, therefore, possible to distinguish slotting allowances that emerge through food processor incentives from the fees driven by noncompetitive retailer motivations by examining the effect of slotting allowances on retail grocery sales, prices, and profits.

Figure 3 depicts annual U.S. grocery sales in the 1966-2000 period for all grocery stores and for supermarkets (in 1982-84 dollars adjusted

\footnotetext{
${ }^{10} \mathrm{It}$ is a somewhat striking result that a retailer oligopoly model with strategic complements results in a qualitatively similar contract outcome as a processor oligopsony model with strategic substitutes. This result obtains because the slope of the reaction functions, in each case, takes the opposite sign as the slope of the function through which market power is derived (i.e., either demand or supply). The qualitative implications of slotting allowances for welfare are opposing in the two models, however; and this is because the effect of a higher wholesale price on market quantity is determined only by whether the equilibrium market quantity is bid along a supply function or a demand function.
} 
by the food-at-home index). The figure shows that annual grocery sales, both in the U.S. grocery market and in U.S. supermarkets, have increased in a fairly stable manner over the period in which slotting allowances emerged. ${ }^{11}$ This increase in sales has matched the general trend in U.S. resident population over the period: grocery and supermarket sales increased by $32.8 \%$ and $37.2 \%$, respectively, compared with a growth rate of $34.2 \%$ in the U.S. resident population. The stability of the trends in retail sales provides some indication that slotting allowances have not decreased the quantity of retail grocery transactions.

Table 1 compares price changes in the consumer price index (CPI) to price trends for all food and food-at-home (FAH) consumption, which excludes food sold in restaurant establishments. Notice that the food-at-home index has not increased relative to the CPI and overall food index in the period. Slotting allowances do not appear to have increased retail grocery prices.

There is also evidence that profit levels increased in the food processing sector relative to the retail grocery sector over the period in which slotting allowances emerged. In the 1961-91 period, Messinger and Narasimhan find that retail profits did not increase, whereas food manufacturer profits did not decrease in the 1980 s relative to earlier periods in their sample.

Overall, the evidence does not seem to support the premise that slotting allowances derive from retailer market power. The trends in retail prices, quantities, and profits provide some indirect evidence that slotting allowances are not motivated by retailer market power. There is also some direct evidence. White, Troy, and Gerlich find slotting allowances to occur predominantly in product categories that are characterized by a large degree of retail competition. A competitive retail market, moreover, would favor processor incentives for slotting allowances.

Slotting allowances that emerge through forces of food processor market power produce retail market features that differ markedly from those obtained through competitive market forces. This is because the slotting allowance, itself, serves as a signaling or

\footnotetext{
${ }^{11}$ The two discontinuities in the supermarket sales data reflect upward revisions in the nominal volume that defined a supermarket. In 1973, the minimum sales volume required to be classified as a supermarket increased from $\$ 0.5$ million to $\$ 1$ million, and, in 1981 , it increased from $\$ 1$ million to $\$ 2$ million.
}

Table 1. The CPI, Food, and Food-at-Home Indexes

\begin{tabular}{|c|c|c|c|}
\hline Year & CPI & Food & FAH \\
\hline 1966 & 100.0 & 100.0 & 100.0 \\
\hline 1967 & 103.1 & 100.9 & 99.7 \\
\hline 1968 & 107.4 & 104.4 & 103.1 \\
\hline 1969 & 113.3 & 109.8 & 108.0 \\
\hline 1970 & 119.8 & 116.0 & 113.4 \\
\hline 1971 & 125.0 & 119.5 & 116.2 \\
\hline 1972 & 129.0 & 124.6 & 121.3 \\
\hline 1973 & 137.0 & 142.6 & 141.2 \\
\hline 1974 & 152.2 & 163.0 & 162.2 \\
\hline 1975 & 166.0 & 176.9 & 175.6 \\
\hline 1976 & 175.6 & 182.2 & 179.3 \\
\hline 1977 & 187.0 & 193.8 & 189.8 \\
\hline 1978 & 201.2 & 213.0 & 209.7 \\
\hline 1979 & 224.1 & 236.4 & 232.4 \\
\hline 1980 & 254.3 & 256.8 & 251.1 \\
\hline 1981 & 280.6 & 276.9 & 269.3 \\
\hline 1982 & 297.8 & 288.2 & 278.7 \\
\hline 1983 & 307.4 & 294.1 & 281.5 \\
\hline 1984 & 320.7 & 305.3 & 292.0 \\
\hline 1985 & 332.1 & 312.4 & 296.3 \\
\hline 1986 & 338.3 & 322.5 & 304.8 \\
\hline 1987 & 350.6 & 335.8 & 317.9 \\
\hline 1988 & 365.1 & 349.7 & 331.3 \\
\hline 1989 & 383.0 & 370.1 & 352.8 \\
\hline 1990 & 403.4 & 391.7 & 375.9 \\
\hline 1991 & 420.4 & 403.3 & 385.8 \\
\hline 1992 & 433.0 & 408.0 & 388.6 \\
\hline 1993 & 446.0 & 416.9 & 398.0 \\
\hline 1994 & 457.4 & 426.9 & 409.4 \\
\hline 1995 & 470.4 & 439.1 & 422.7 \\
\hline 1996 & 484.3 & 453.6 & 438.4 \\
\hline 1997 & 495.4 & 465.4 & 449.1 \\
\hline 1998 & 503.1 & 475.4 & 457.7 \\
\hline 1999 & 514.2 & 485.5 & 466.5 \\
\hline 2000 & 531.5 & 496.4 & 477.0 \\
\hline
\end{tabular}

Notes: Data are from the U.S. Bureau of Labor Statistics (http://www. bls.gov/data/sa.htm). All price indexes are for all urban consumers; the U.S. city average is in 1966 dollars. $\mathrm{CPI}=$ the consumer price index. Food $=$ the food index, including food at home. $\mathrm{FAH}=$ the food-at-home index.

screening device under asymmetric information, whereas, under processor market power, the lump-sum payment plays only an indirect role in supporting a higher wholesale price. It follows that evidence to differentiate slotting allowances that emerge through processor incentives from the fees that arise through competitive market forces can be found by examining changes in the dynamic profile of wholesale grocery prices. A slotting contract motivated by processor market power must narrow the gross retail margin in contracted categories of the supermarket by (17).

Sullivan examines a composite measure of the gross retail margin across all supermarket products and argues that the nondecreasing 
gross retail margin identified over the 1961-86 period supports the competitive market view. There are at least three reasons why this is not the case. First, the 1961-86 period largely preceded the emergence of slotting allowances in 1984. Indeed, an increase in the gross retail margin over this period would provide precisely the type of change in processor incentives that could explain the appearance of slotting allowances. Second, this period is characterized by a rapid increase in the number of grocery products stocked. For example, between 1978 and 1987, A. C. Nielsen reports a $34.4 \%$ increase in the number of dry grocery items stocked in grocery stores and numerous trade articles report similarly high growth rates in the number of frozen and refrigerated items stocked in supermarkets in the 1980s. Given the relatively capital-intensive nature of frozen and refrigerated products, this is likely to have substantially increased retailer fixed costs. In the absence of lump-sum transfers, an increase in retailer fixed costs would tend to increase the gross retail margin across supermarket products, and, for this reason, evidence in time series data on the (net) change in the gross retail margin is largely uninformative. Third, the gross retail margin across all supermarket products is a measure that aggregates over a large set of product categories, only a subset of which employ slotting allowances. To derive evidence on the linkage between slotting allowances and gross retail margins for this subset of products, cross-sectional data are required.

Table 2 compares gross retail margins for a selection of products in which the magnitudes of slotting allowances are known. Notice that the refrigerated/frozen-foods category has higher slotting fees than the candy/snacks category, but that the retail margins for the refrigerated/frozen-foods category are notably smaller. Higher, still, is the gross retail margin for the in-store bakery category, a product category with neither slotting allowances nor the element of market intermediation necessary to support them under oligopsony incentives.

A necessary condition for slotting allowances to emerge through oligopsony market power is intermediation between the farm product market and the wholesale grocery market. For this reason, it is useful to compare trends in gross retail margins between processed and nonprocessed product categories of the supermarket in time series data. Figure 4 compares the relative trends in the gross retail margins for fresh and frozen vegetables over

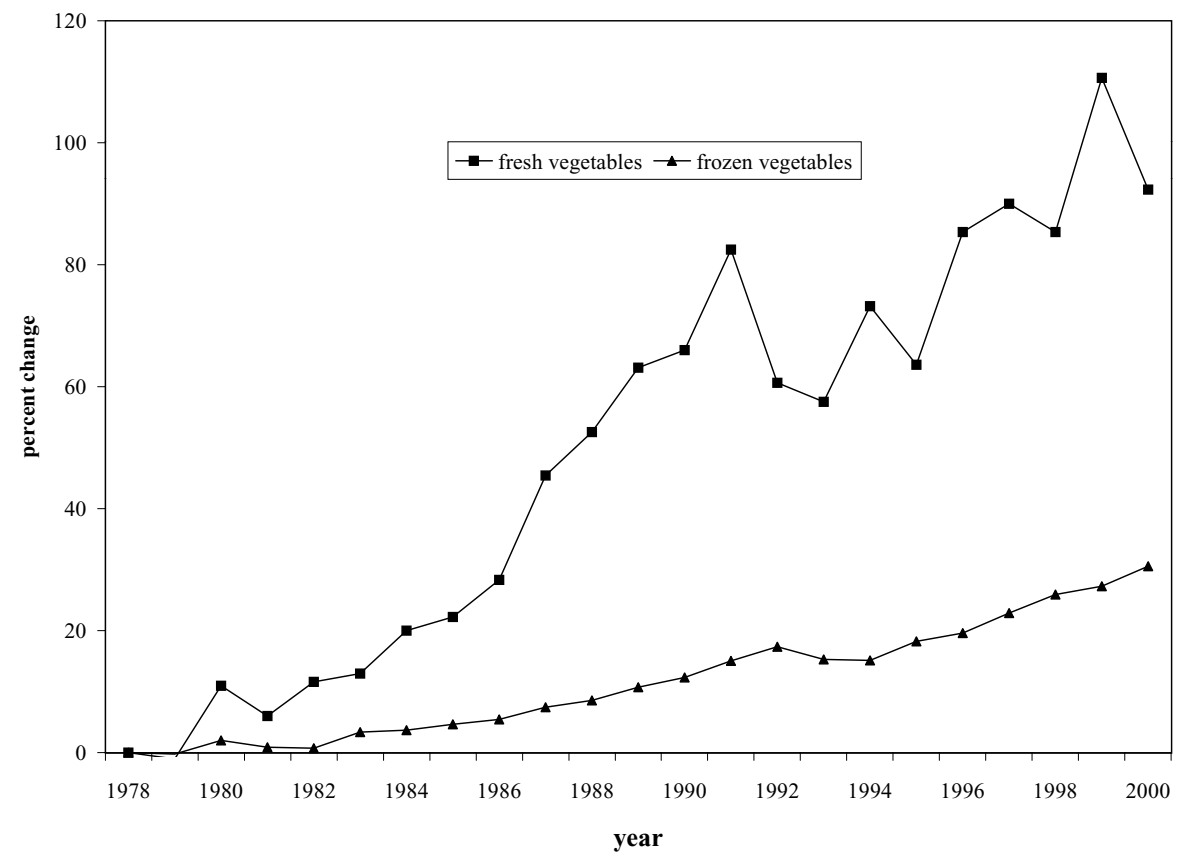

Source: U.S. Bureau of Labor Statistics

Figure 4. Percent change in gross retail margins for fresh and frozen vegetables, 1978-2000 
Table 2. Sample Slotting Allowances and Gross Retail Margins, 1997

\begin{tabular}{lclc}
\hline Product Category & $\begin{array}{c}\text { Slotting } \\
\text { Allowance }\end{array}$ & \multicolumn{1}{c}{ Subcategory } & $\begin{array}{c}\text { Gross Retail } \\
\text { Margin (percent) }\end{array}$ \\
\hline Refrigerated and Frozen Foods & $\$ 40,000$ & Dairy products & 29.8 \\
Candy/Snacks & $\$ 7,000$ & Frozen foods & 31.7 \\
& & Crackers, cookies, biscuits & 33.9 \\
& & Sweet goods & 39.2 \\
In-store Bakery & \multirow{2}{*}{ None } & Chewing gum & 35.3 \\
\hline
\end{tabular}

Source: Desiraju.

Note: Slotting allowances are reported on a per item per store basis.

the 1978-2000 period. ${ }^{12}$ The gross retail margin in each product category is taken to be the difference between the CPI and producer price index (PPI), where the relative difference in the producer and consumer price for each series is normalized to zero in 1978 . Notice that the gross retail margin for fresh vegetables increased substantially relative to that for frozen vegetables in the period. This is consistent with a central prediction of the model that slotting allowances motivated by oligopsony market power lead to a narrowing of the gross retail margin on processed food products relative to nonintermediated farm commodities.

\section{Concluding Remarks}

This article has demonstrated that slotting allowances may be motivated, not by grocery retailers who wish to receive the fees, but by food processors who wish to pay them. The central observation that supported this result is that a slotting allowance paid in exchange for a retail concession that induces an upward shift in a food processor's marginal value product function enables the processor to obtain greater oligopsony rent in the farm product market.

The retail concession acquired through a slotting allowance was formally modeled as a higher wholesale price. While this form of retailer concession corresponds with an important contract form observed in wholesale grocery transactions - a fixed price contractslotting allowances, in general, need not be structured in this form. A slotting allowance may also be paid by a food processor in exchange for a variety of other retail concessions, such as to acquire a relatively more desirable shelf space position in the supermarket (e.g., at basket level on the corner of an aisle) or to

\footnotetext{
${ }^{12}$ The gross retail margin for frozen vegetables is used to proxy that for all processed vegetables. Prior to 1997, the U.S. Bureau of Labor Statistics does not report price data on canned vegetables nor on all processed vegetables.
}

exclude rival processors from obtaining shelf space through an exclusive territory arrangement. Nonetheless, to the extent that a retail concession of any form induces an outward shift in the marginal value product function of the contracted processor, qualitatively similar results to those obtained here would continue to arise.

Slotting allowances that derive from oligopsony market power were found to have positive implications for economic surplus at all stages of the food system. The noncooperative Nash contract equilibrium of the model was shown to involve multilateral slotting allowances by food processors that raise farm surplus, increase the combined surplus of farmers, processors, and retailers, and improve consumer welfare.

The model results suggest some interesting possibilities for future research into the nature of wholesale grocery transactions. Along theoretical lines, considerable research is needed to develop a greater conceptual understanding of the forces at work in the highly differentiated retail grocery sector. In the case of slotting allowances, there is little evidence of the practice at volume retailers like Wal-Mart and Costco, which suggests a potential link may exist between wholesale pricing arrangements and inventory management practices at the retail level. In general, the marketing environment of multiproduct food retailers is a much-understudied area, particularly in noncompetitive contexts, and adding structural detail to this sector in vertical models may provide important insights into explaining the multitude of market practices that continue to materialize in an increasingly sophisticated food system.

Further empirical research is needed to develop an adequate understanding of slotting allowances. This article has outlined several possibilities in this direction by identifying several features that distinguish slotting allowances produced under processor incentives 
from those derived under alternative market forces. Namely, processor incentives for slotting allowances require an element of intermediation between the farm product market and the wholesale market and are promoted by elastic retail demand conditions, inelastic farm supply conditions, and large retail margins. Ex post, the effect of slotting allowances was shown to narrow retail margins, and evidence was provided that the gross retail margin substantially decreased in the frozen vegetables category relative to that in the fresh vegetables category in the period that slotting allowances emerged.

An alternative explanation for the recent narrowing of the gross retail margin on processed foods relative to commodities is the proliferation of branded, processed goods. To the extent that product proliferation makes retail demand (per brand) more elastic, an increase in the variety of processed products would place downward pressure on the gross retail margin for processed goods relative to commodities. It is interesting to note that this trend toward differentiated processed goods may be related to the emergence of slotting allowances. An increase in the elasticity of retail demand would provide a larger incentive for food processors to employ slotting allowances, which suggests that a potentially important nexus may exist that links the coincident trends toward slotting allowances and product proliferation in the processed product categories.

\section{References}

Baumol, W.J., and D.F. Bradford. "Optimal Departures from Marginal Cost Pricing." American Economic Review 60(1970):265-83.

Bonanno, G., and J.S. Vickers. "Vertical Separation." Journal of Industrial Economics 36(1988):257-65.

Cannon, J.P., and P.N. Bloom. "Are Slotting Allowances Legal Under Antitrust Laws?" Journal of Public Policy \& Marketing 10(1991):167-86.

Calvin, L., R. Cook, M. Denbaly, C. Dimitri, L. Glaser, C. Handy, M. Jekanowski, P. Kaufman, B. Krissoff, G. Thompson, and S. Thornsbury. U.S. Fresh Fruit and Vegetable Marketing: Emerging Trade Practices, Trends, and Issues. Washington DC: U.S. Department of Agriculture, ESCS For. Agr. Econ. Rep. 795, January 2001.

Chen, Z., and R. Lent. "Supply Analysis in an Oligopsony Model.” American Journal of Agri- cultural Economics 74(1992):973-79.

Coughlin, A.T., and B. Wernerfelt. "On Credible Delegation by Oligopolists: A Discussion of Distribution Channel Management." Management Science 35(1989):226-39.

Desiraju, R. "New Product Introductions, Slotting Allowances and Retailer Discretion." Journal of Retailing 77(2001):335-58.

Dixit, A., and J. Stiglitz. "Monopolistic Competition and Optimal Product Diversity." American Economic Review 67(1977):297-308.

Hamilton, S.F., and D.L. Sunding. "The Effect of Farm Supply Shifts on Concentration and Market Power in the Food Processing Sector." American Journal of Agricultural Economics 80(1998):830-38.

Hamilton, S.F., and K. Stiegert. "Vertical Coordination, Antitrust Law, and International Trade." Journal of Law \& Economics 43(2000):143-56.

Just, R.E., and W. Chern. "Tomatoes, Technology, and Oligopsony." Bell Journal of Economics 11(1980):584-602.

Lariviere, M.A., and V. Padmanabhan. "Slotting Allowances and New product Introductions." Marketing Science 16(1997):112-28.

Lin, J.Y. "Oligopoly and Vertical Integration: Note." American Economic Review 78(1988):251-54.

Messinger, P., and C. Narasimhan. "Has Profit Shifted in the Grocery Channel?" Marketing Science 14(1995):189-223.

Progressive Grocer. Annual Report of the Grocery Industry (April issues 1971-2001).

Richards, T., and P. Patterson. "Slotting Allowances as Real Options: An Alternative Explanation." Journal of Business, in press

Shaffer, G. "Slotting Allowances and Resale Price Maintenance: A Comparison of Facilitating Practices." RAND Journal of Economics 22(1991):120-35.

Sexton, R. "Imperfect Competition in Agricultural Markets and the Role of Cooperatives: A Spatial Analysis." American Journal of Agricultural Economics 72(1990):709-20.

Sullivan, M.W. "Slotting Allowances and the Market for New Products." Journal of Law \& Economics 40(1997):461-93.

U.S. Bureau of Labor Statistics. Consumer Price Index. http://www.bls.gov/data/sa.htm (accessed on 15 March 2001).

Wann, J., and R. Sexton. "Imperfect Competition in Multiproduct Food Industries with Application to Pear Processing." American Journal of Agricultural Economics 74(1992):980-90.

White, J.C., L.C. Troy, and R.N. Gerlich, "The Role of Slotting Fees and Introductory Allowances in Retail Buyers' New-Product Acceptance Decisions." Journal of the Academy of Marketing Science 28(2000):291-98. 